\title{
Artigos
}

\section{Magnan e a classificação das patologias psiquiátricas}

\author{
Magnan and the classification of psychiatric pathologies
}

\author{
SANDRA CAPONI \\ Universidade Federal de Santa Catarina | UFSC
}

\begin{abstract}
RESUMO A teoria da degeneração teve influência considerável na psiquiatria dos séculos XIX e XX. Essa teoria começou a articular-se na segunda metade do século XIX na França, fundamentalmente com os estudos de Morel e de seu discípuloValentin Magnan. Analisamos aqui a construção, consolidação e impacto desse programa de pesquisa a partir das reflexões que Magnan dedica às patologias heredodegenerativas incluídas na sua classificação das doenças psiquiátricas. Esse modo de classificar os sofrimentos e comportamentos torna possível que os pequenos desvios de conduta, os estigmas físicos e psíquicos, e em menor medida os delírios insignificantes, possam começar a serem considerados como patologias ou como signos anunciadores de alienação mental.
\end{abstract}

Palavras-chave degeneração - herança - psiquiatria ampliada - classificação; patologia

\begin{abstract}
The Degeneration Theory had a large influence in the Psychiatry of the XIXth and XXth Centuries. This theory was articulated during the second half of the XIXth Century in France, primarily through the studies of Morel and his disciple, Valentin Magnan. We analyze here, the construction, consolidation and impact of this program of research using as a main reference, Magnan's examinations of the Inherited Degenerative Disorders that were included in his classification of Psychiatric Diseases. This way of classifying the sufferings and behaviors made possible for small behavioral deviances, physical and psychic stigmas, and, to a lesser degree, insignificant delusions, to be considered as pathologies or as signals that announced mental alienation.
\end{abstract}

Key words degeneration - heredity - extended psychiatry - classification; pathology

\section{INTRODUÇÃO}

Nas últimas duas décadas do século XIX multiplicaram-se os debates referentes ao problema da classificação das doenças mentais, particularmente em torno de uma das categorias propostas por Benedict August Morel em seu texto de 1857, Traité des dégénérescences physiques, intellectuelles et morales de I'espèce humaine, ${ }^{1}$ as chamadas 'loucuras de degeneração'. 
A partir de 1880, surge a necessidade de criar uma classificação de doenças mentais que possa vir a ser universalmente aceita pela psiquiatria mundial. Inicialmente, essa proposta foi apresentada pela Sociedade Belga de Psiquiatria, que submeteu à apreciação da comunidade internacional sua classificação de doenças. Com a finalidade de apreciar essa proposta ou de criar uma própria, a Sociedade Médico-Psicológica francesa nomeou uma comissão que teria a tarefa de unificar em um sistema classificatório as diferentes abordagens sobre normalidade e loucura defendidas pelos psiquiatras franceses. Em 1887 a sociedade designou uma comissão composta por três membros: Paul Garnier, Valentin Magnan e Jules Christian. Dentre eles, destacava-se a figura de Magnan, então presidente da Sociedade. Essa comissão apresentou uma classificação de patologias que era quase idêntica à defendida por Magnan em suas aulas, textos e artigos. ${ }^{2}$

Essa classificação foi submetida à crítica pelos pares em 1888. 0 eixo central do debate continuava sendo a velha teoria da degeneração de Morel, ferrenhamente defendida por Magnan, seu discípulo mais destacado, em todos os foros de psiquiatria, tanto francesa quanto mundial. No entanto, a classificação proposta pela comissão foi rejeitada e duramente criticada pelos membros da Sociedade, o que significava que a França era incapaz de estabelecer um consenso sobre uma classificação única de patologias mentais que pudesse ser apresentada perante a comunidade internacional. No entanto, ainda que a proposta da comissão não fosse aceita em sua totalidade, muitos psiquiatras abraçaram a ideia das patologias heredodegenerativas e aceitaram as premissas fundamentais da teoria da degeneração. Alguns destacaram a necessidade de integrar as doenças adquiridas na primeira infância, outros somaram as doenças adquiridas nos meses de gravidez, outros as que surgem no momento do parto. Mas a maior parte dos psiquiatras parecia aceitar esse grupo patológico denominado 'loucuras hereditárias' (sinônimo para Magnan de 'loucuras de degeneração ${ }^{\prime 3}$ ). Tratava-se de um grupo que incluía grande parte das desordens mentais que não pareciam ter lugar nas classificações psiquiátricas clássicas.

Para compreender esse debate que ocorre após a morte de Morel, será necessário analisar de que modo essa nova configuração patológica das degenerações hereditárias ingressa nas classificações psiquiátricas. Os Anais Médico-Psicológicos publicaram diversos artigos dedicados ao problema da degeneração que, nas últimas décadas do século XIX, se transformou em um frutífero programa de pesquisa que congregava médicos, neurologistas e psiquiatras. Novas síndromes de degeneração ocuparam as páginas dos Anais, e uma variedade de bizarros quadros patológicos multiplicou-se entre 1870 e 1890. Como afirma Coffin, esse fenômeno persistiu até as primeiras décadas do século XX:

A noção de degeneração transformou-se no novo paradigma de análise social. Todos os fenômenos com os quais a sociedade devia confrontar-se eram questionados a partir dessa perspectiva sombria. A natalidade baixa? É a confirmação da degradação biológica da raça francesa. O número de alcoólatras aumenta? Representa uma França que degenerará no futuro. Os escritores já não sabem escrever? Seu estado mental os faz ineficientes para a produção artística. Os exemplos podiam multiplicar-se ao infinito. ${ }^{4}$

Vamos nos deter aqui na figura de Magnan e na persistência da problemática da degeneração nos Anais Médico-Psicológicos. No entanto, é preciso lembrar que o interesse por esse programa de pesquisa não foi exclusivo da psiquiatria francesa. Algo semelhante ocorrerá na Alemanha, com Max Nordau (1849-1923), na Itália, com Lombroso (1835-1909) e na América Latina, por exemplo, no Brasil, com Nina Rodrigues (1862-1906).

0 sucesso desse programa de pesquisa deveu-se ao fato de que ele parecia ser frutífero para explorar patologias não incluídas nas classificações clássicas, definir anomalias físicas, mentais e morais, circular entre o espaço estritamente médico e as intervenções sociais. 0 programa de pesquisa dedicado ao problema da degeneração inclui questões referentes à purificação das raças, à mestiçagem, aos programas eugênicos, assim como a questões relacionadas à higiene pública e à medicina social. Esse programa configura uma biopolítica da população que diz respeito a povos e grupos considerados como desvios da média. Porém, este estudo centra-se no impacto que a problemática da degeneração teve no campo da psiquiatria, especificamente, no modo de classificar as patologias mentais. 
A teoria da degeneração apresentava-se como um fundamento científico sólido para legitimar as intervenções médicas sobre condutas de indivíduos e grupos. Esse programa reforçava a crença de neurologistas e psiquiatras de que, mais cedo ou mais tarde, seria possível achar no corpo, particularmente no cérebro e nas conexões neurais, a explicação para os mais variados desvios de conduta.

Analisamos o impacto da teoria da degeneração nas novas classificações de patologias mentais que surgem nas últimas décadas do século XIX como resposta às classificações psiquiátricas de Pinel e Esquirol, centradas na teoria das monomanias. Tanto Morel quanto Magnan, por razões diversas e com argumentos diferentes, destacaram a insuficiência das classificações sintomáticas da psiquiatria clássica que multiplicavam monomanias a partir de um sintoma que se destacava (mania de perseguição, loucura de dúvida, megalomania etc.). Ambos consideravam urgente a tarefa de substituir essa classificação por outra, capaz de definir e agrupar as patologias em função de suas causas e não de seus sintomas, destacando a relevância da herança mórbida como eixo articulador da cadeia causal de patologias psiquiátricas.

A seguir analisa-se a classificação psiquiátrica proposta por Magnan e o lugar reservado às loucuras heredodegenerativas. Deveremos deter-nos também na leitura dos Anais Médico-Psicológicos e dos Anais de Higiene e Medicina Legal, pois ambos dedicam uma considerável quantidade de artigos ao problema da degeneração, evidenciando que se trata de uma temática que suscitará interesse até 1920. Analisa-se, por fim, a relevância teórica e epistemológica da teoria da degeneração e de suas derivações no nascimento da psiquiatria moderna.

\section{Valentin Magnan e as patologias heredodegenerativas}

Ainda que Magnan (1835-1916) seja considerado o maior discípulo de Morel, seu interesse pela problemática da degeneração começou tardiamente. Seus trabalhos inicialmente publicados nos Anais Médico-Psicológicos eram dedicados ao estudo da paralisia geral e à problemática do alcoolismo. A partir dessas duas temáticas privilegiadas de pesquisa, Magnan confronta-se com as dificuldades e limites das classificações de patologias mentais existentes, sendo particularmente crítico da classificação sintomática de monomanias proposta por Esquirol.

As pesquisas dedicadas à paralisia geral tinham levado Magnan a interessar-se cada vez mais pelo estudo do cérebro, por sua anatomia, suas funções e os efeitos das lesões cerebrais. Esses estudos evidenciavam a necessidade de estabelecer um diálogo entre a medicina mental e a neurologia. A psiquiatria começava a apresentar um interesse crescente pelos estudos de localização cerebral que, a partir de Gall e Broca, pareciam trazer novas possibilidades de pesquisa para patologias mentais e físicas. Desse otimismo fala Magnan na apresentação de um de seus cursos:

Senhores, nós estamos em dívida com a anatomia-patológica por uma das mais belas conquistas que hoje temos em psiquiatria. Falo da paralisia geral (...). O que podemos afirmar sem temor é que as pesquisas atentas das lesões anatômicas e também a pesquisa, lamentavelmente negligenciada, das modificações químicas que ocorrem na intimidade dos tecidos cerebrais, poderão conduzir-nos à determinação dessas formas mentais tão distintas e tão claramente definidas que caracterizam a paralisia geral. ${ }^{5}$

No entanto, as explicações referidas à localização de lesões cerebrais, útil no caso da paralisia geral, permaneciam ainda como uma grande incógnita quando se tratava das patologias mentais em geral. 0 otimismo sobre as infinitas possibilidades que trariam os estudos de localização cerebral iniciados nas primeiras décadas do século XIX começava a ser, pouco a pouco, questionado. Já não resultava tão simples imaginar que no futuro se acharia uma lesão cerebral específica para cada patologia mental, diferentemente do que ocorria no caso da paralisia geral. Porém, será a partir dos estudos sobre paralisia geral que Magnan ingressará no território da psiquiatria. Nesse momento ele enuncia o que 
serão seus principais desafios teóricos: levar a medicina mental ao território da psiquiatria experimental e fundamentar as explicações etiológicas de doenças mentais no campo da patologia cerebral.

Se a relação lesão cerebral/paralisia geral podia parecer promissora e frutífera, Magnan logo verificará as dificuldades de reproduzir esse mesmo modelo nas pesquisas sobre alcoolismo. Ainda assim, seus estudos sobre alcoolismo Ihe deixarão dois prêmios, um da Academia de Medicina e outro da Academia de Ciências, ambos em $1872 .{ }^{6}$ E será a partir desse momento que esse membro destacado da Sociedade Médico-Psicológica iniciará as pesquisas sobre a relação entre alcoolismo e degeneração. Lembremos que também foi com estudos sobre o alcoolismo que Morel iniciou suas reflexões sobre a degeneração. Magnan analisa as conseqüências mentais do abuso de álcool, os delírios provocados pelo consumo excessivo, e apresenta estudos estatísticos dos alienados internos nos asilos, indicando a quantidade de alcoólatras que se encontram nessas instituições. Tanto para Magnan como para Morel, o alcoolismo devia ser entendido como uma patologia eminentemente hereditária. Para ambos era necessário estudar as alterações cerebrais que provocavam delírios, ainda que não se pretendesse achar, como no caso da paralisia geral, uma lesão cerebral específica para a doença.

As preocupações de Magnan podem resumir-se em: determinar o caráter hereditário do alcoolismo; estudar a associação desse comportamento com os delírios e a alienação mental; definir as alterações cerebrais que apresentam esses doentes. Por essa razão, seu texto principal, denominado Recherches sur les centres nerveux, publicado em 1893 como síntese de seus trabalhos anteriores, leva como subtítulo Alcoolismo, loucuras dos heredodegenerados, paralisia geral e medicina legal.

A primeira parte dessa obra é inteiramente dedicada ao tema do alcoolismo, considerado como o problema social mais grave ao qual deveria se dedicar a medicina mental. Afirma que o alcoolismo não é um fato individual, com consequências limitadas ao sujeito que bebe; pelo contrário, trata-se de uma doença que afeta profundamente os descendentes e as sucessivas gerações, levando consigo a degradação da raça. ${ }^{7}$ Por essa razão, como mostram os estudos estatísticos, mais de 35\% dos doentes internados em asilos psiquiátricos estão ali pelos delírios provocados pelo álcool. Magnan apresenta características psíquicas e físicas dos indivíduos afetados, divididos em quatro categorias conforme o tempo, os delírios recorrentes e as afecções físicas que podem conduzir à paralisia geral ou à demência. Essa intoxicação provoca sérias alterações no sistema nervoso central, derivadas, para Magnan, da falta de equilíbrio das funções cerebrais que indicam "uma implacável marcha clínica à demência". ${ }^{8}$

Os estudos de anatomia patológica feitos nos cadáveres de alcoólatras evidenciam a olho nu, em todos os órgãos (fígado, rim, coração, cérebro), características específicas. Sendo que em nenhuma outra afecção "encontram-se desse modo associadas, em diversos órgãos, a esteatose e a esclerose intersticial difusa". ${ }^{9}$

Diferente de Morel, o interesse de Magnan não era teórico ou especulativo, mas descritivo. Ele não pretendia criar um sistema explicativo geral ou um fundamento metafísico da psiquiatria. Não compartilhava com seu mestre a ideia de um tipo originário, normal, da humanidade que teria se degradado, provocando uma multiplicidade de patologias ou loucuras de degeneração. Seu trabalho, alheio a especulações metafísicas, era apresentado como empírico e clínico, e estava direcionado a responder a três questões articuladoras: fundamentar a teoria da degeneração na anatomiapatológica, questionar o lugar que o degenerado deveria ocupar na sociedade e criar uma classificação unificadora das patologias mentais capaz de integrar as loucuras hereditárias ou degenerativas (para ele, sinônimos), superando os limites das classificações existentes.

Ainda que o estudo sobre as degenerações se iniciasse com o alcoolismo, sua entrada definitiva nesse território temático foi consolidada com seu trabalho dedicado a um quadro patológico que parecia concentrar todos os estigmas da degeneração: o idiotismo. Ele representava, tanto para Magnan quanto para Morel, o grau mais avançado e grave das degenerações. A partir do estudo desse quadro patológico, Magnan ingressa no estudo do que chamará, seguindo Morel, de 'loucuras morais'. 


\section{Degenerações e desequilíbrio cerebral}

Magnan dedica a segunda parte do livro Recherches sur les centres nerveux ao problema dos degenerados, que considera o mais delicado para psiquiatras e higienistas. As articulações entre degeneração e alcoolismo são inúmeras pelas consequências que tal patologia provoca na saúde mental dos pacientes, tais como delírios, alucinações, excitação maníaca etc. Por outra parte, Magnan considera que o alcoolismo é hereditário, agravando-se 0 estado do indivíduo nas sucessivas gerações de alcoólatras e provocando, na descendência, inúmeras degenerações, tanto físicas quanto morais.

Ainda que os alcoólicos pertençam ao grupo dos degenerados hereditários, o primeiro grau da degeneração corresponde ao idiota. De fato, o primeiro grupo dessa categoria imensa e heterogênea dos degenerados hereditários é composto por três figuras: o 'idiota', o 'imbecil' e o 'débil mental'. Já o último grupo na escala gradativa das degenerações é composto pelos chamados 'loucos morais'. Integram esse grupo sujeitos com manias de perseguição, hipocondria, delírios de grandeza e aqueles que padecem tanto de manias de excitação como de depressão melancólica.

Os grupos que compõem a grande categoria de loucuras heredodegenerativas estão ordenados de acordo com uma lógica de gravidade decrescente, ficando no topo da degeneração o grupo que se caracteriza por concentrar todos os estigmas físicos, mentais e morais. Para construir esse quadro, Magnan faz um estudo comparativo entre o idiota e outras figuras patológicas, como o demente e o sujeito que padece de paralisia cerebral. Ele afirma que:

No grau mais profundo de idiotismo, o sujeito está privado de toda relação com o exterior. Seus olhos vagos olham, mas não enxergam; a mucosa olfativa e a língua parecem normais, mas não sente nem o perfume nem o gosto (...). Ele não é surdo, mas o barulho o deixa indiferente. Utiliza inutilmente sua força muscular em movimentos de balanço monótonos e reiterativos. Não fala, emite gritos ou pronuncia somente monossílabos. ${ }^{10}$

0 que caracteriza esse grupo, para Magnan, é o fato de que todos os aparelhos sensoriais externos têm uma perfeita conformação, porém estão vinculados ao comando de um sistema nervoso central que é defeituoso. No caso dos idiotas, Magnan afirma que existem lesões no córtex cerebral que são adquiridas por herança ou por doenças ocorridas na primeira infância. Magnan diferencia esse quadro patológico da demência, caracterizada pela debilidade da memória, a capacidade de juízo associada a instintos pervertidos ou anulados. Diz que os indivíduos primitivamente inteligentes que por uma lesão cerebral se transformam em dementes são diferentes clinicamente daqueles que padecem de miséria intelectual congênita e não adquirida, como é o caso dos idiotas.

Relata casos de pessoas diagnosticadas como idiotas que, no entanto, apresentam certas habilidades. Por exemplo, é possível achar indivíduos que se destacam como pintores, escultores, músicos etc. Se isso é possível é porque, segundo Magnan, esses sujeitos conservam intactos os centros periféricos do ouvido, do tato ou da visão. Assim, os quadros de idiotismo podem apresentar características diversas. À pergunta de por que razão não existe o idiotismo ou a imbecilidade com caracteres essenciais constantes, como acontece com a paralisia geral, responde afirmando:

Ocorre que na paralisia geral a lesão é única e idêntica, uma encefalite crônica intersticial de andamento progressivo. Não é o mesmo caso no idiota, ou na imbecilidade, como nós vimos, não existe uma lesão orgânica única capaz de produzir essas degenerações, elas se derivam de diferentes fontes que não respondem a nenhuma sistematização. ${ }^{11}$

De modo que nas degenerações uma região do encéfalo pode estar afetada e outra ficar completamente normal, como é o caso do idiota pintor ou do idiota músico.

Se o que unifica essa ampla categoria dos degenerados não é uma lesão orgânica, cabe interrogar-se pelo fundamento científico desse agrupamento patológico. Magnan não estava disposto a renunciar às explicações médicas nem 
à anatomia patológica. Uma coisa parecia certa, seu caráter hereditário: "o que não pode deixar de ser dito é que as degenerações mentais são, de um modo ou outro, patologias hereditárias". ${ }^{12} 0$ caráter hereditário das degenerações abre a possibilidade de prevenir a inexorável marcha da doença: "o degenerado hereditário está em um perpétuo estado de iminência mórbida". ${ }^{13}$ Isso significava que todo degenerado deveria ser considerado um doente em potencial, que representava uma ameaça que devia ser antecipada e evitada, ainda que os estigmas físicos ou psíquicos não tivessem se manifestado.

0 imenso agrupamento mórbido dos degenerados ou dos loucos hereditários inclui entre seus extremos, que vão do idiota ao deprimido, uma amplíssima gama de sujeitos e uma imensa variedade sintomática. 0 que unifica essa imensa variedade é um conjunto de traços sociais e comportamentais, amplos e vagos, tais como um julgamento pouco sólido, um senso moral imperfeito que pode levá-lo a ingressar na via do crime; um escasso senso de responsabilidade. Porém, Magnan considera que existe um traço comum mais marcante: a 'irresistibilidade', isto é, a incapacidade para resistir aos seus impulsos. Uma limitação da liberdade de ação, apesar de existir consciência dessa limitação.

Assim, o impulsivo homicida, o cleptomaníaco, o incendiário, o exibicionista, os anormais sexuais, os idiotas etc., tivessem ou não estigmas físicos, podiam juntar-se ao grupo dos heredodegenerados. Observando um desses casos,

(...) já não nos pode surpreender a linguagem do cleptomaníaco, do piromaníaco, do impulsivo homicida ou sexual, do exibicionista ou do desgraçado obcecado pela ideia de morder a pele de uma jovem mulher, quando eles declaram que, apesar de todos os seus esforços, de seu ardente desejo de resistir, eles terminaram por sucumbir aos impulsos. ${ }^{14}$

Todos compartilham um mesmo impulso irresistível de cometer certos atos independentes de sua vontade, de comportar-se de um modo que, muitas vezes, eles mesmos rejeitam conscientemente, mas se sentem internamente obrigados a fazê-lo. 0 tipo normal da humanidade, ao qual se referia Morel, não desapareceu completamente. Já não se trata de um modelo criado por Deus, mas de um modelo socialmente desejado: 0 indivíduo capaz de agir de acordo com normas sociais estabelecidas, sem se submeter a impulsos ou desejos involuntários.

Como já adiantamos, as características comportamentais dos degenerados deviam ser pensadas sob o marco da anatomia-patológica. Por essa razão, cada um dos relatos clínicos de Magnan deverá seguir a mesma sequência lógica. Inicia com a descrição dos comportamentos bizarros que caracterizam o indivíduo e logo os membros de sua família, relatam-se os sintomas clínicos, para imediatamente descrever os estudos de anatomopatologia cerebral feitos nos cadáveres de sujeitos afetados pelos mesmos males. Um elemento permite unificar todos esses quadros patológicos em uma mesma classificação: a anatomia-patológica permite evidenciar a existência de um centro cerebral sobreestimulado que demanda satisfação imediata. 0 que define o quadro patológico das degenerações não é a localização de uma lesão cerebral comum, e sim uma ideia introduzida por Magnan: a ideia de equilíbrio ou desequilíbrio, também mencionada como harmonia ou desarmonia cerebral.

Os degenerados hereditários constituem uma grande família patológica, claramente definida, que tem caracteres próprios que a distinguem de qualquer outra espécie mórbida. (...) No caso dos degenerados, todos os sintomas repousam sobre um fundo especial: o desequilíbrio mental. Os degenerados são os únicos alienados nos quais se faz evidente o desequilíbrio mental. ${ }^{15}$

Para compreender de que modo se unificam síndromes diversas (como a cleptomania, a síndrome da dúvida ou a ninfomania) na categoria classificatória dos degenerados hereditários, devemos entender o lugar que ocupa a desarmonia cerebral no pensamento de Magnan. Para ele, todo degenerado é um desequilibrado, isto é, um sujeito cujas funções cerebrais encontram-se desvinculadas entre si ou estão desvinculadas das funções do sistema nervoso central. Os caracteres sintomáticos da degeneração se dividem em três grupos: os estigmas físicos, os estigmas psíquicos e os delírios. Pode ocorrer que os estigmas físicos não sejam evidentes, às vezes se tratam de alguns sinais 
pouco visíveis, como a forma das orelhas, certo estrabismo, algum vício de conformação do crânio. Por vezes esses estigmas são extremamente evidentes, como no grupo dos chamados 'idiotas'. A demência pode aparecer em algumas ocasiões de modo evidente; em outras, de modo sutil. Porém, o que sempre existirá, de acordo com Magnan, são os estigmas psíquicos que aparecem sob a forma de comportamentos bizarros, mas que, na verdade, não são mais que 0 modo como se manifestam as patologias cerebrais. Magnan considera que o desrespeito às normas sociais é indicativo de uma síndrome psíquica, mas a última palavra será dada pela fisiologia ou patologia cerebral identificando um desequilíbrio ou uma desarmonia.

A neurofisiologia da degeneração considera que cada território cerebral tem uma função específica, e que o correto funcionamento do cérebro resulta da perfeita articulação de cada função cerebral. A atividade normal supõe uma vinculação harmônica entre os diferentes centros cerebrais e a medula espinhal. Se uma dessas funções está perturbada, ocorrerá desarmonia cerebral. Isso implica que os diferentes sistemas que constituem o conjunto da conexão cérebro espinhal não estão interligados de modo correto. Para Magnan, o que unifica todos os degenerados é que eles compartilham certos estigmas psíquicos a partir dos quais se manifesta uma conexão deficiente entre as diferentes partes do cérebro. Por essa razão, é possível achar um sujeito com certos momentos de lucidez e outros de delírio. Momentos nos quais as conexões neurais ocorrem corretamente, e outros momentos em que elas deixam de ocorrer.

Essa representação cerebral inscreve-se na mesma lógica de outros estudos da época, nos quais pouco a pouco as esperanças em achar para cada patologia uma lesão cerebral se desvanecem. A desarmonia ou o desequilíbrio substituem a busca por lesões específicas. Todos os casos relatados por Magnan têm o objetivo de mostrar que, por trás da herança patológica e dos estigmas psíquicos, encontra-se um mesmo fundamento anatomopatológico: 0 desequilíbrio cerebral. A partir dessa constatação, os conceitos de louco hereditário, degenerado ou desequilibrado passarão a ser utilizados como sinônimos intercambiáveis. ${ }^{16}$

0 desequilíbrio permite entender a diversidade sintomática das degenerações em função da parte do cérebro afetada; permite entender o tipo de impulso ou de obsessão que move a ação do indivíduo em uma ou outra direção. Também explica por que razão podem conviver diversos sintomas em um mesmo sujeito e por que aparecem quadros patológicos sucessivos em um mesmo indivíduo ao longo de sua vida. 0 desequilíbrio tem formas múltiplas de manifestar-se, configurando diversos quadros sintomáticos, aos quais Magnan dá o nome de 'síndromes'. Em função dessas síndromes, como veremos, será construída a classificação de patologias mentais de Magnan.

\section{As síndromes de degeneração na classificação de Magnan}

Está fora do objetivo deste estudo fazer uma análise minuciosa das classificações psiquiátricas que se sucederam nos séculos XIX e XX, tarefa que reclama um estudo mais detalhado. 0 objetivo aqui é menos ambicioso. Pretende-se compreender o lugar que ocupam as degenerações na classificação psiquiátrica de Magnan. Ele divide as patologias psiquiátricas em três grandes grupos: as loucuras hereditárias ou degenerações; as loucuras intermitentes e o delírio crônico ou psicose..$^{17}$ Ainda que essa classificação sofra modificações ao longo dos anos, existem questões que permanecem constantes.

Uma dessas constantes é o interesse em substituir a classificação das monomanias de Esquirol, que até então era a mais utilizada; outra ideia que permanece é que todas as patologias mentais são hereditárias, e que a herança de caracteres similares é mais evidente nos degenerados; por fim, a distinção entre as degenerações hereditárias (ou loucuras hereditárias, ou desequilíbrios) dos delirantes crônicos ou psicóticos se manterá inalterada. Magnan reconhece que não é simples separar um grupo de outro somente pelo caráter hereditário da patologia. Ele afirma que quem fala de psicose, fala de doença hereditária. Porém, no caso da degeneração, a herança atua em um grau muito mais considerável. Evidencia-se a herança similar, fundamentalmente em certos fenômenos bizarros e nas síndromes episódicas, que são os estigmas psíquicos. ${ }^{18}$ Ele afirma que as mesmas compulsões que caracterizam os pacientes, como o medo 
de tocar o veludo ou o pânico de alfinetes, por exemplo, se repetem na mãe ou na irmã mais velha. Ocorre o mesmo com as compulsões sexuais ou criminosas.

Esse quadro sintomático que se repete de geração em geração, às vezes de modo idêntico, às vezes associado a outros sintomas, permite criar esses agrupamentos patológicos denominados de 'síndromes'. Devemos destacar que esses conjuntos de sintomas, chamados estigmas psíquicos, como roubar, ter medo de sair da casa, limpar obsessivamente as mãos, consumir abusivamente álcool ou outros tóxicos (como cocaína ou absinto), não constituem patologias definidas, são simplesmente quadros sintomáticos ou síndromes. Essas síndromes possuem duas características principais: são evolutivas e são irreversíveis, ainda que existam alguns modos de atenuá-las ou diminuí-las, tais como as estratégias utilizadas nos asilos: duchas, isolamento etc. A evolução ocorre de duas formas. Pode acontecer que a síndrome fique cada vez mais grave de geração em geração ou que se sucedam síndromes de gravidade crescente ao longo da vida do mesmo indivíduo, em um escalonamento patológico indefinido.

A partir de 1882, Magnan se dedicará ao estudo das perversões sexuais, quadro sindrômico variado que faz parte do grupo das degenerações hereditárias. Ele vai trabalhar diretamente com neurologistas reputados, como Charcot, ${ }^{19}$ com quem escreve vários artigos nos Anais Médico-Psicológicos. A ambição de Magnan era achar para cada patologia (dentre elas as patologias sexuais) uma lesão cerebral precisa, e, ao mesmo tempo, definir para cada comportamento sexual uma forma clínica. ${ }^{20}$ Surge assim uma série de síndromes bizarras, como 0 onanismo, a pederastia, a sodomia, 0 fetichismo, a necrofilia, a gerontofilia, entre outras. Cada um desses comportamentos não define uma patologia específica; essas síndromes são formas pelas quais se manifesta uma doença profunda, que é a loucura dos degenerados. É verdade que sempre existiram vínculos entre loucura e sexualidade. Porém, os comportamentos sexuais nunca tinham sido tão minuciosamente classificados em categorias patológicas como ocorreu nesse momento. Como afirma Coffin, "com esse gesto se produz a incontestável patologização dos comportamentos cotidianos". ${ }^{21}$

Surgem, dentro dessa mesma lógica explicativa, outras síndromes, como, por exemplo, a loucura dos antivivisseccionistas. ${ }^{22}$ Esse quadro patológico tão particular aparece como uma resposta, considerada extrema ou exagerada, a um sentimento respeitável que as sociedades modernas começavam a ter em relação às brutalidades cometidas contra os animais. Com esse objetivo foram criadas diversas sociedades de proteção aos animais que, em princípio, perseguiam fins legítimos. Porém, Magnan entende que "nessa corrente de ideias que os cativa, seres extremamente sensíveis, com um cérebro mal equilibrado, os degenerados, acham seus temas de preocupação e os exageram até transformá-los em verdadeiros delírios". ${ }^{23}$ Magnan dirá que não podemos falar de um quadro patológico específico, que se trata de uma síndrome que pode aparecer conjuntamente com outros sintomas.

Inicialmente deveremos dizer que não se trata de uma espécie patológica nova, é simplesmente uma síndrome episódica, uma das manifestações variadas pelas quais se traduz uma loucura hereditária ou, se vocês preferem, um dos estigmas psíquicos da loucura hereditária. ${ }^{24}$

Ele não duvida em criar, ao lado desse quadro patológico, como sendo da mesma natureza e respondendo à mesma lógica, outra síndrome episódica: a 'loucura dos vegetarianos'. Ela ocorria com um tipo peculiar de vegetarianos, sujeitos que optavam por comer somente vegetais para evitar o sacrifício inútil dos animais, radicalizando as premissas das sociedades protetoras.

Se essas síndromes resultam hoje absurdas, não é menos estranho um quadro patológico criado por Magnan, ao qual dedica vários artigos e um capitulo de livro: a 'onomatomania'. Trata-se de uma preocupação com as palavras que chega a provocar angústia. Isso acontece, segundo Magnan, em situações específicas, tais como: (1) a busca angustiosa de uma palavra ou de um nome; (2) um impulso irresistível a repetir certas palavras; (3) o uso de palavras inadequadas (obscenas) em uma conversação. Como no caso da síndrome de antivivissecção, a onomatomania não deve ser considerada uma espécie patológica nova, mas um grupo de sintomas que se articulam, neste caso específico, em torno dos nomes ou palavras. Do mesmo modo que nos outros casos, trata-se de uma síndrome indicativa de uma patologia mais ampla e profunda que é a degeneração. 
Por onomatomania não queremos designar uma patologia nova, queremos destacar um grupo de sintomas nos quais a palavra, o nome, cumpre um papel preponderante. Isso se observa em sujeitos elevados na escala das degenerações mentais (os desequilibrados) e constitui uma síndrome episódica da loucura hereditária. ${ }^{25}$

Essas síndromes, como a loucura de dúvida, as anomalias sexuais, a loucura racional ou a loucura de antivivissecção, somente podem se desenvolver em sujeitos com predisposição mórbida. Trata-se de diferentes estigmas psíquicos que adota a degeneração hereditária.

0 prestígio de Magnan como presidente da Sociedade Médico-Psicológica permitiu que suas ideias se transformassem em um verdadeiro programa de pesquisa para psiquiatras, médicos, neurologistas e juristas. No entanto, esse prestígio não foi suficiente para impedir que detratores e críticos levantassem sólidos argumentos contra a teoria da degeneração. Em 1888, realizou-se na Sociedade Médico-Psicológica de Paris um debate sobre o tema da degeneração. ${ }^{26}$ Dentre as alocuções de médicos e psiquiatras, destaca-se a de Jules Falret. ${ }^{27}$ Ele apresenta um resumo das divergências que alguns membros da Sociedade tinham em relação às teorias defendidas por Morel e Magnan. Em seu texto, Recherches sur les centres nerveux, Magnan retoma essa discussão e responde às críticas de Falret.

Podemos diferenciar três grandes problemas articuladores desse debate. A primeira objeção de Falret se refere à extensão, quase ilimitada, dos agrupamentos patológicos que entram na categoria psiquiátrica de loucuras de degeneração. Para ele seria necessário excluir alguns sujeitos cujo 'único pecado' é ter algumas características físicas ou do caráter que podem parecer bizarras, mas que não configuram uma verdadeira alienação mental. Nada justificaria 0 internamento desses sujeitos em asilos de tratamento psiquiátrico.

A essa objeção Magnan responde com um exemplo. Imaginemos um sujeito que trabalha, cumpre suas obrigações, tem uma família, é reconhecido pelos colegas, mas que, no entanto, possui uma irresistível tentação de pronunciar certas palavras obscenas ou de gritar sem razão. 0 que diferenciaria esse sujeito de outro que não sente vontade de gritar ou de pronunciar certas palavras, mas que sente a mesma vontade irresistível de bater nas pessoas que passam a seu lado? Para Magnan, não existem diferenças entre ambos: tanto um quanto o outro sofrem de uma síndrome de degeneração, a onomatomania no primeiro caso e a compulsão à violência no segundo. "Esses dois sujeitos, o que pronuncia uma palavra apesar de sua vontade e o que bate nos outros apesar de sua vontade pertencem ao mesmo grupo. A natureza do fenômeno é a mesma, ainda que as consequências sejam diferentes" ${ }^{28}$ Nos dois casos existe um esforço irreprimível por realizar uma ação vinculada a um centro nervoso que está superestimulado. Com esse argumento, Magnan rejeita a petição de Falret de excluir os sujeitos que têm predisposições mórbidas leves da classificação dos degenerados hereditários e, consequentemente, do mundo dos alienados mentais.

A segunda crítica de Falret refere-se à desnecessária inclusão de algumas patologias, já bem definidas e conhecidas pela psiquiatria clássica, dentro do grupo das degenerações. Um caso é a 'doença da dúvida', que, segundo Falret, deveria ser definida como uma patologia independente. Ainda que essa doença tenha algumas peculiaridades que a diferenciam da outras degenerações, Magnan considera que se deve manter como uma síndrome episódica dentro do grupo das degenerações. Dirá que, frequentemente, a doença da dúvida está associada ao medo de tocar objetos ou pessoas e a delírios relacionados a esse medo. Afirma que essa patologia não se apresenta de modo isolado, que é comum estar associada a outros quadros sintomáticos que aparecem sucessivamente ou concomitantemente em um mesmo indivíduo. A crítica de Falret permite que Magnan retome seu alvo privilegiado de ataque, as monomanias de Esquirol:

A principal vantagem do estudo dos degenerados hereditários é reunir em um mesmo quadro síndromes que têm manifestações diferentes, mas que surgem de um fundo comum. (...) Porque o eixo cérebro-espinhal encontra-se em desequilíbrio, ocorrem esses fenômenos bizarros que são as síndromes episódicas, que adotam a forma de obsessão ou impulso. Essas síndromes se desenvolvem unicamente nos degenerados e devem ser consideradas como estigmas psíquicos da degeneração. (...) Se as observações antigas deixam a desejar nesse ponto é porque se fazia das monomanias, das doenças distintas, verdadeiras 
abstrações que não deixavam lugar para identificar o fundo comum que é o traço de união entre essas manifestações tão variadas. ${ }^{29}$

Como afirma Déricq, ${ }^{30}$ na abertura do curso de Magnan de 1885 publicada nos Anais Médico-Psicológicos, existem dois métodos para estudar as patologias mentais. Um se refere ao grande complexo sintomático pelo qual se manifestam as patologias. Nesse caso, separa-se o sintoma que mais se destaca em um quadro patológico, que se eleva à categoria de entidade mórbida. Esse é o caso da agorafobia, da cleptomania etc. Pode ocorrer também que as patologias sejam separadas por uma multiplicidade de causas simples, como é o caso da loucura uterina. Esse método de isolar as patologias pelos sintomas ou pela origem biológica tem como resultado um conjunto confuso de doenças, chamadas 'monomanias'. 0 outro método é o modelo seguido por Magnan, que permite constituir uma espécie patológica articulando todos os elementos que possuem certa relevância. “Cada fenômeno é visualizado no tempo, transformando-se não em uma entidade mórbida, mas em uma face de uma doença maior". ${ }^{31}$ Assim, a resposta à segunda crítica de Falret transforma-se, de fato, na defesa de um modelo classificatório das patologias que se opõe ao modelo hegemônico de classificação por monomanias.

Por fim, a terceira crítica de Falret, ${ }^{32}$ provavelmente a mais difícil de responder, refere-se à debilidade e à precariedade dos estudos de anatomia patológica existentes. Falret insiste sobre as dificuldades para definir a localização cerebral das degenerações hereditárias. Magnan reconhece que ainda existem múltiplas dúvidas sobre como localizar no cérebro as degenerações ou desequilíbrios. Considera que, no entanto, existem grandes conquistas, tais como a descoberta da localização cerebral da capacidade de fala ou a localização dos centros psicomotores; destaca os avanços possibilitados pelo estudo da afasia e de outras patologias cerebrais. Conclui sua exposição afirmando que sua resposta permitirá o desaparecimento das dissidências, por outro lado secundárias, que existem entre ele e Falret.

Ainda que Magnan considere essas dissidências pouco significativas, Falret aponta os três maiores problemas da teoria da degeneração. Essas três grandes dificuldades teóricas acompanharão, mais tarde, a moderna psiquiatria ampliada. Nem a teoria da degeneração nem a psiquiatria dos comportamentos atualmente existente poderão dar resposta a essas questões apontadas por Falret: a dificuldade para demarcar os limites, pouco claros e difusos, que separam os pequenos desvios cotidianos dos sofrimentos psíquicos profundos; a insistência em pensar as patologias mentais como uma sucessão de entidades mórbidas que se manifestam em um mesmo indivíduo ao longo de sua vida (fazendo de cada pequeno desvio a advertência de uma grave patologia por vir); a busca, reiteradamente fracassada, pela localização cerebral de uma multiplicidade de síndromes pouco claras e indefinidas. As dificuldades apontadas por Falret, como as fronteiras difusas entre o normal e o patológico e as esperanças ilimitadas na descoberta de novas localizações cerebrais de sofrimentos psíquicos, continuarão sendo minimizadas ou desconsideradas pela psiquiatria pelos próximos 150 anos.

Para concluir este item, dedicado ao modo como Magnan classifica as loucuras de degeneração, apresentamos o Tableau synoptique des dégénérescences mentales: lês héréditaires degeneres, publicado em seu livro Recherches sur les centres nerveux. ${ }^{33}$

\section{Quadro sinótico das degenerações mentais}

\section{Os heredodegenerados ${ }^{34}$}

I - Idiotismo, imbecilidade e debilidade mental.

II - (Desequilibrados) Anomalias cerebrais: defeito no equilíbrio das faculdades morais e intelectuais.

III - Síndromes episódicas hereditárias

(1) Loucura da dúvida

(2) Temor do toque: acmofobia 
(3) Onomatomania: 1) busca angustiosa de uma palavra, 2) impulso irresistível de repetir uma palavra, 3) medo de usar palavras comprometedoras etc.

(4) Aritmetomania

(5) Ecolalia, coprolalia, com falta de coordenação motora (Gilles de La Tourette)

(6) Amor exagerado pelos animais: loucuras dos antivivissecionistas

(7) Dipsomania, Sitiomania (alimentos)

(8) Cleptomania, oniomania (mania de compras)

(9) Mania de jogar

(10) Piromania e pirofobia

(11) Impulsos homicidas e suicidas

(12) Anomalias, perversões aberrações sexuais: a. medula espinhal (reflexo simples; centro genitoespinhal de Büdge); b. cérebro-espinhal posteriores (reflexo cortical posterior); c. cérebro-espinhal anterior (reflexo cortical anterior); d. Cerebrais anteriores (erotomania)

(13) Agorafobia, claustrofobia, topofobia

(14) Abulia.

IV - (a) Mania raciocinante, loucura moral (perseguidos-perseguidores)

(b)Delírio primário múltiplo: delírio ambicioso, hipocondríaco, religioso, de perseguição;

(c) Delírio sistemático único, fixo, sem tendências evolutivas. Análogo às ideias obsessivas e

(e) Excitação maníaca, depressão melancólica.

Trata-se, como já foi dito, de um esquema que apresenta os quadros patológicos em gravidade decrescente. Síndromes e delírios não são facilmente diferenciáveis, pois, como afirma Magnan, muitas síndromes se apresentam conjuntamente com delírios ou manias. De igual modo, a palavra desequilibrados é utilizada tanto para o subgrupo assim definido como para caracterizar uma peculiaridade das loucuras de degeneração em sua totalidade. Os degenerados sempre apresentam, para Magnan, algum tipo de desequilíbrio mental e, por essa razão, pouco a pouco, o termo 'desequilibrado' substituirá 'degenerado'. Esse esquema explicativo das patologias psíquicas será retomado por alunos e discípulos de Magnan, transformando-se no eixo articulador do programa de pesquisa sobre degenerações já iniciado por Morel em 1857, como fica evidente quando observamos a multiplicidade de textos sobre essa temática publicados nos Anais de Higiene e Medicina Legal e nos Anais Médico-Psicológicos.

\section{O desenvolvimento de um programa de pesquisa}

Esse esquema sofrerá alterações nos anos posteriores a sua publicação: novas síndromes serão inseridas, existirão novos agrupamentos patológicos, o espectro das doenças mentais continuará se ampliando e aparecerão novos dados empíricos tendentes a confirmar as classificações de Morel e Magnan. Independentemente das muitas críticas dirigidas à teoria da degeneração, podemos afirmar que, inicialmente com a publicação do Tratado de Morel ${ }^{35}$ e, a partir de 1870, com os trabalhos de Magnan, configura-se um novo modo de pensar as doenças mentais que inclui, junto com os delírios e as alucinações, um conjunto pouco claro e indefinido de comportamentos considerados síndromes de degeneração. 
Nas últimas décadas do século XIX, a psiquiatria estará fortemente influenciada por essa nova representação das patologias que fala das degenerações hereditárias. Surge uma imensa diversidade de estudos preocupados em esclarecer e descobrir novas síndromes e estigmas físicos e psíquicos. lan Hacking ${ }^{36}$ dirá que nesse momento se inicia um verdadeiro 'programa de pesquisa' frutífero, capaz de concentrar os esforços de médicos, higienistas, juristas e psiquiatras que compartilhavam uma mesma preocupação: a de ampliar a abrangência e os limites da medicina mental. Foucault entende que "a degeneração é a peça teórica maior que permite a medicalização do anormal. 0 degenerado é 0 anormal miticamente - ou, se vocês preferem, cientificamente - medicalizado". ${ }^{37}$

Podemos verificar o alcance desse programa de pesquisa na França observando 0 amplo espectro de síndromes que, como vimos, se incluem nessa classificação: não somente as manias de perseguição, as aberrações sexuais, as anomalias de comportamento e uma imensa variedade de medos e temores, como também as características bizarras da onomatomania, do vegetarianismo, da compulsão pelo roubo ou do alcoolismo.

Analisando a sucessão de trabalhos publicados nos Anais de Higiene e Medicina Legal e nos Anais Médico-Psicológicos, podemos observar a relevância dessa problemática para a medicina mental e legal, e sua permanência ainda nas primeiras décadas do século XX. Verificamos uma repetição quase obsessiva de artigos dedicados à degeneração que, com temáticas semelhantes, foram publicados desde 1858 até 1924.

Assim, nos Anais de Higiene e Medicina Legal, periódico publicado entre 1829 e 1922, o primeiro texto dedicado a essa temática é um extenso comentário bibliográfico ao livro de Morel, que aparece na edição número 9 de $1858 .{ }^{38}$ Nos números seguintes veremos reaparecerem inúmeras referências a essa temática. A partir de 1860, sucedem-se diversos textos dedicados a diferentes temas vinculados à degeneração. Destacamos aqui algumas dessas publicações: na edição número 22 de 1864 aparece um artigo dedicado à pretensa degeneração da população francesa, no qual 0 autor estabelece comparações com outros países de Europa;39 as referências à degeneração social e ao alcoolismo são recorrentes, sendo particularmente significativo um artigo referente à degeneração hereditária dos alcoólatras. ${ }^{40}$ A preocupação com a degeneração e a herança reaparece por referência a diversas doenças, como é 0 caso da sífilis ${ }^{41}$ ou da epilepsia. ${ }^{42}$ Outros autores multiplicam as associações entre degeneração e os mais variados desvios, tais como as ideias persecutórias, a depressão melancólica, a debilidade mental congênita ou idiotismo.

No caso específico dos Anais Médico-Psicológicos, publicados na França entre 1843 e 1953, a preocupação com a temática da degeneração começa com um texto do próprio Morel, no qual ele apresenta um informe sobre essa questão. Esse texto é um breve resumo das principais ideias desenvolvidas em seu livro. ${ }^{43}$ Neste caso os textos referentes à temática da degeneração se repetem com maior frequência (chegando a ser registradas mais de 350 ocorrências). Essa sucessão de textos permanece até 1924.

As associações são extremamente diversas e vão desde estudos dedicados à relação alcoolismo/degeneração até as mais variadas associações com comportamentos e síndromes. Dentre estas podemos destacar: distrofia sexual ${ }^{44}$ criminalidade ${ }^{45}$ prostituição; ${ }^{46}$ neuroses, psicoses, delírio de autoacusação; amnésia: ${ }^{47}$ atos inconscientes, fugas e delírio de persecução;48 loucura maníaco-depressiva; ${ }^{49}$ suicídio; síndrome obsessivo-compulsiva, na qual 0 autor relata o caso de um homem obcecado pela limpeza; até a publicação de uma história da ideia de degeneração em medicina mental..$^{50}$

Nos Anais Médico-Psicológicos não aparecem somente relatos de indivíduos e famílias de degenerados: diversos escritos estão relacionados à degeneração dos povos e raças. Particularmente se destacam alguns textos dedicados a analisar a degeneração intelectual do povo francês que se apresentam como uma contribuição à saúde mental dos povos, ${ }^{51}$ utilizando como referência o famoso texto de Paul Broca. ${ }^{52}$

Ainda que apareçam algumas críticas pontuais, a maior parte dos textos relata casos e tipos diversos do que se denominava "loucura de degeneração". Lembremos que a teoria da degeneração é solidária a essas duplicidade e ambiguidade que caracterizam os conceitos de norma e normalidade. A categoria 'degeneração' refere-se a um duplo desvio: por um lado, desvio da frequência estatística desejada em relação a características físicas tais como altura, 
peso, formato do rosto, das orelhas etc., os chamados 'estigmas físicos' ou stigmatas; 53 por outro, desvio das normas ou valores socialmente estabelecidos os 'estigmas psíquicos', como a tendência à criminalidade, as aberrações sexuais, os delírios de persecução ou dúvida, as onomatomanias. A teoria da degeneração postulava intrincadas relações entre características físicas e fatos morais. Essas relações, que eram mais evidentes no discurso de Morel, estão longe de desaparecerem na teoria de Magnan. Para ele a inexistência de estigmas físicos não deveria ser considerada relevante quando apareciam estigmas psíquicos, tendência ao roubo, por exemplo. Porém, a existência de estigmas físicos sempre era indicativa de um processo de degeneração.

Nos Anais Médico-Psicológicos existem diversos textos dedicados a analisar essa relação. Um deles é o estudo de Knecht sobre degeneração e criminalidade publicado em 1885, que apresenta dados estatísticos sobre a relação entre degeneração física e moral:

As observações referem-se a 1.214 homens, dentre os quais aparece tudo o que é anormalidade de altura, conformação exterior do corpo, do crânio, do rosto, dos órgãos genitais, dos dedos, das orelhas etc. 579 indivíduos, ou seja, 48\% do conjunto dos criminais apresentam desvios do tipo normal. A partir desses dados e considerando a falta de autopsias, pode-se concluir por indução que existem também numerosos desvios nos órgãos internos. ${ }^{54}$

Para Magnan, existem três características sintomáticas da degeneração. Além dos estigmas físicos e dos estigmas psíquicos já analisados, existe um terceiro elemento que completa o quadro patológico: os delírios. 0 delírio cumpre uma função peculiar na teoria das degenerações hereditárias. De fato ele pode existir ou não. É possível imaginar uma síndrome, como a loucura da dúvida, por exemplo, na qual não existam delírios. No entanto, por tratar-se de um processo mórbido evolutivo, o delírio sempre está presente no âmbito das possibilidades. Os delírios que aparecem no último grupo das degenerações hereditárias são os que permitem vincular o degenerado com as psicoses, isto é, com o quadro dos chamados delírios crônicos. Assim, a síndrome da dúvida poderá juntar-se ao delírio de voar ou a delírios sexuais. Como as alucinações que acompanham a psicose, os delírios constituem a ponte entre os quadros patológicos da psiquiatria clássica e as novas configurações patológicas pelas quais se manifestam as loucuras de degeneração. Representam uma possibilidade futura, uma ameaça que reclama, legitima e justifica a intervenção psiquiátrica e 0 internamento asilar. ${ }^{55}$

0 que aparece como relevante a partir desse momento não é saber se estamos ou não perante um delírio, mas "o desvio que uma conduta representa em relação às regras de ordem, de conformidade, definidas sob um fundo de regularidade administrativa, de obrigações familiares ou de normatividade política e social" ${ }^{56}$

A partir desse momento, a psiquiatria mudará radicalmente seu objeto de estudo, assim como mudará suas estratégias de intervenção. Seu interesse já não será restabelecer a saúde perdida, mas antecipar todo e qualquer tipo de anomalia: "Tudo o que é desordem, indisciplina, agitação, indocilidade, caráter reativo, falta de afeto etc., tudo de aqui em diante poderá ser psiquiatrizado". ${ }^{57}$

\section{Ao modo de conclusão: a medicalização dos desvios}

Analisamos aqui a construção do programa de pesquisa sobre a degeneração tal como aparece na França. ${ }^{58}$ Porém, existiram seguidores dessas teorias no mundo inteiro. Podemos observar a permanência desses debates não somente na Itália, Inglaterra ou Alemanha, mas também no Brasil, Argentina, México e Colômbia. De igual modo, as temáticas abordadas foram múltiplas, o problema da degeneração e a questão da raça foram objetos privilegiados de preocupação de autores como Nina Rodrigues ${ }^{59}$ no Brasil, enquanto a criminalidade e a loucura foram a maior preocupação de José Ingenieros ${ }^{60}$ na Argentina. 
Como já foi dito, foge às possibilidades deste estudo analisar a multiplicidade de questões abordadas sob a temática da degeneração. 0 objetivo que perseguimos foi explicitar as bases teóricas e epistemológicas que possibilitaram que os comportamentos cotidianos, os pequenos desvios, as loucuras menores, ingressassem no campo de saber e de intervenção psiquiátrica.

A teoria da degeneração permite que os pequenos desvios de conduta, os estigmas físicos ou psíquicos e, em menor medida, os delírios insignificantes, se transformem em signos anunciadores de alienação mental. 0 tratamento imaginado por Magnan era sempre o internamento psiquiátrico. Para ele não existiam diferenças entre aquele indivíduo que consegue levar uma vida familiar e de trabalho, mas não pode dominar a compulsão em enunciar certas palavras; aquela mulher que escolhe alimentar-se exclusivamente de comida vegetariana para evitar a violência contra os animais e aquele indivíduo que sofre alucinações caracterizando um quadro psicótico.

Sobre essa identificação entre condutas cotidianas e patologia psiquiátrica foram construindo-se as bases epistemológicas da psiquiatria moderna que, seguindo Foucault, denominamos psiquiatria ampliada.

Dir-se-á que o discurso da degeneração desaparece do âmbito da psiquiatria nas primeiras décadas do século XX. Pode-se afirmar que existe uma radical ruptura entre o discurso metafísico de Morel, as classificações sindrômicas de Magnan e os agrupamentos patológicos da psiquiatria atual. Não se pretende desconsiderar as diferenças entre esses discursos. No entanto, é possível afirmar com Coffin ${ }^{61}$ que a degeneração não desaparece simplesmente do âmbito da psiquiatria. Ela sofre transformações, adota novos nomes, impulsiona novas estratégias de ação, mas deixa marcas indeléveis na história da psiquiatria.

Seja sob o nome de desequilíbrios, de predisposições hereditárias ou de configurações patológicas, a psiquiatria continuará interessada em desvendar os mesmos segredos que alentaram o programa de pesquisa das degenerações: a relação entre patologias psiquiátricas e herança mórbida, a construção de uma psiquiatria preventiva atenta ao caráter evolutivo das patologias e a busca pela localização cerebral de sofrimentos psíquicos. Após as críticas dirigidas a Magnan pela ilimitada expansão de patologias psiquiátricas, novos nomes surgiram, tornando o quadro patológico das degenerações hereditárias aceitável. A teoria da degeneração, mais que rejeitada, será pouco a pouco substituída. Como afirma Coffin, a palavra degeneração recua perante outros termos, como 'predisposição hereditária' ou 'psicose constitucional', proposto por Ballet. ${ }^{62}$

Além das críticas de Falret já analisadas, a teoria da degeneração foi alvo de diversos questionamentos que destacavam a abusiva extensão das alienações mentais a partir da introdução das patologias de degeneração. Nessa linha argumentativa, Charpentier advertia em 1885 para as consequências de aceitar, sem questionamentos, uma classificação de doenças mentais que inclui as doenças heredodegenerativas. Magnan assim transcreve essas críticas de Charpentier:

Tenhamos cuidado com essa tendência (da psiquiatria), ou então as loucuras da infância, as da adolescência, todos os problemas mentais consecutivos e os hábitos repetidos ou as costumes inveteradas, tiques, monomanias, todas as perturbações mais ou menos conhecidas da vontade, da consciência, dos estados emocionais, todas as faltas de equilíbrio, já seja das faculdades entre si, já seja com as faculdades afetivas e morais (...) apesar de suas causas freqüentemente permaneçam ignoradas, supressão do fluxo normal (menstruação ou esperma), ou causas mórbidas (hemorróidas, suor ou problemas cutâneos); todas essas perturbações terão um lugar nas loucuras hereditárias que, desse modo, vai devir um verdadeiro caput mortuum destinado a recolher tudo aquilo que não poderá corresponder convenientemente a um dos capítulos conhecidos da medicina mental..$^{63}$.

Para Charpentier, a teoria da degeneração ou das patologias heredodegenerativas permite uma extensão abusiva do domínio da psiquiatria, permite criar um grupo indefinido de 'loucuras disparatadas'. Nessa lógica classificatória, cada conduta, gesto, tique poderá passar a ser indicativo de uma síndrome, resultando impossível diferenciar um adolescente melancólico pela influência da leitura de romances, das aberrações sexuais monstruosas cometidas por um 
psicótico. ${ }^{b l}$ A teoria da degeneração permite e legitima a existência de fronteiras difusas entre o normal e o patológico, possibilitando a ingerência do saber médico nos pequenos medos e angústias cotidianas, nos estados de tristeza, nas situações de dúvida, enfim, nos pequenos desequilíbrios cotidianos.

\section{Notas e referências bibliográficas}

Sandra Caponi é doutora em Lógica e Filosofia da Ciência pela UNICAMP, pós-doutora pela EHESS (Paris, França). É professora associada da Universidade Federal de Santa Catarina. E-mail: sandracaponi@gmail.com.

Agradeço aos pareceristas pela atenta leitura e pelas pertinentes contribuições e observações realizadas.

1 MOREL, Benedict August. Traité des dégénérescences physiques, intellectuelles et morales de I'espèce humaine et des causes qui produisent ces varieties maladives. Paris: Baillière, 1857.

2 RITTI, A. Comptes rendus. In: CONGRES INTERNATIONAL DE MEDECINE MENTAL, 1889, Paris, Masson; GARNIER, P. Classification des maladies mentales. In: Annales Médico-Psycologiques. Paris, Masson, 1888 ,n. 8, p. 454-468.

3 MAGNAN,Valentin. Recherches sur les centres nerveux. Alcoolisme, folie des héréditaires dégénérés. 2. ed. Paris: Masson, 1876-1893, p. 9. COFFIN, Jean. La transmission de la folie - 1850-1914. Paris: Ed. Harmattan, 2003, p. 191. Tradução do autor.

Ibid., p. 124.

Ibid., p. 128.

MAGNAN, op. cit., p. 9.

Ibid., p. 93.

Ibid., p. 96

Ibid., p. 401.

Ibid., p. 112.

Ibid., p. 112.

Ibid., p. III.

Ibid., p. V.

Ibid., p. 135.

COFFIN, op. cit., p. 106.

Ibid., p. 144.

ver MAGNAN, op. cit., p. 138

MAGNAN, Valentin ; CHARCOT, Jean-Martin. De I'onomatomanie. Archives de neurologie, v. 23, n. 69, 1892.

COFFIN, op. cit., p. 128.

Ibid., p. 131.

MAGNAN, op. cit., p. 150.

Ibid., p. 269.

Ibid., p. 270.

Ibid., p. 279

RITTI, A., op. cit.; GARNIER, op. cit.

FALRET, Jules. Chronique du Congrès International de Médecine Mental. Annales Médico-Psycologiques, no. 9, 1889. p. 177-186.

MAGNAN, op. cit., p. 121.

Ibid., p. 192.

DÉRICQ, Lucien. Leçon d'aouverture du cours de M. Magnan sur les maladies mentales. Annales Médico-Psicologiques. Paris: Masson, n. 2, 1885. p. 311. Id.

FALRET, op. cit.

MAGNAN, op. cit., p. 150.

Ibid., p. 150. Tradução do autor.

MOREL, op. cit.

HACKING, lan. Múltipla personalidade. Rio de Janeiro: José Olympio, 2000.

FOUCAULT, Michel. Les anormaux. Paris: Seuil, 1999; Historia de la sexualidad. México: Siglo XXI, 1978. v. 1.

ANDRAL, Gabriel. Rapport sur le traite de degenerescence physiques, intellectuelles et morales. Annales D 'Hygiéne Publique et de Médecine Legal. Paris: 
Baillière, 1858. n. 9, p. 490-493.

LEGOYT, Michel. De la pretendu dégénérescénce physiques de la population française. Annales D’Hygiéne Publique et de Médecine Legal. Paris: Baillière, 1864. n. 22, p. 221-223.

40 LEGRAIN, Paul Maurice. Dégénérescénce sociale et alcoolisme physiques. Annales D 'Hygiéne Publique et de Médecine Legal. Paris: Baillière, 1895. n. 34, p. 372.

41 BROUARDEL, Jules. Dégénérescénces hérédo-syphilitiques. Annales D’Hygiéne Publique et de Médecine Legal. Paris: Bailliére, 1899. n. 42, p. 503-506.

42 BEAUSSART, Paul. Epilepsie et dégénérescénce mental. Annales D 'Hygiéne Publique et de Médecine Legal. Paris: Bailliére, 1912. n. 17, p. 59-63.

43 MOREL, op. cit.

44 KIRN, L. Dégénérescénces graves dans sés rapports avec psychoses. Annales Médico-Psicologiques. Paris: Masson, 1870. n. 7, p. 316.

45 FERÉ, Charles. Dégénérescence et criminalité. Annales Médico-Psicologiques. Paris: Masson, 1890. n. 6, p. 354.

46 LAURENT, Emil. Prostitution et degeneration. Annales Médico-Psicologiques. Paris: Masson, 1899. n. 10, p. 381.

47 COWLES, James. Epilepsie avec amnésie. Annales Médico-Psicologiques. Paris: Masson, 1904. n. 20, p. 318.

48 FILLASSIER, Alfred Dégénérescence mentale avec épilepsie, actes inconscientes, fugues, impulsions. Annales Médico-Psicologiques. Paris: Masson, 1909. n. 10, p. 304-305.

49 HAMEL, Henri. Dégénérescence et folie maníaco-depressive. Annales Médico-Psicologiques. Paris: Masson, 1911. n. 13, p. 308.

50 GENIL-PERRIN, Georges. Histoire des origines et de l'evolution de l'idée de dégénérescence. Annales Médico-Psicologiques. Paris: Masson, 1914. n. 5, p. 216-218.

51 STARCK, Carl. La dégénérescence intellectuelle du peuple français. Annales Médico-Psicologiques. Paris: Masson, 1884. n. 5, p. 292

52 BROCA, Paul. Sur la prétendu dégénérescence de la population française. Paris: Martinet, 1867.

53 CARTRON, Laure. L'idée de dégénérescence au XIX. In: SEMINAIRE DE G. JORLAND. Paris, EHESS, 2000.

54 FERÉ, Charles. Dégénérescence et criminalité. Annales Médico-Psicologiques. Paris: Masson, 1890. n. 11, p. 150-155.

55 MAGNAN, op. cit., p. 173-175.

56 FOUCAULT, Michel, op. cit., p.147.

57 Ibid., p. 150.

58 Ver MAGNAN, Valentin ; LEGRAIN, Paul-Maurice. Les degeneres: état mental et syndromes épisodiques. Paris: Rueff, 1895.

59 NINA RODRIGUEZ, Raimundo. Os mestiços brasileiros. Gazeta Médica da Bahia, v. 21, n. 11, p. 197-503,1890.

60 INGENIEROS, José. La locura em Argentina. Buenos Aires: Cooperativa Editorial Limitada, 1920.

61 COFFIN, op. cit., p. 256.

62 Ibid., p. 235.

63 MAGNAN, op. cit., p. 130. Tradução do autor.

64 Ibid., p. 131.

[Recebido em novembro de 2010, aprovado para publicação em fevereiro de 2011] 